\title{
Spatial ecology study reveals nest attendance and habitat preference of banded kraits (Bungarus fasciatus)
}

\author{
TYLER K. KNIERIM ${ }^{1 *}$, COLIN T. STRINE', PONGTHEP SUWANWAREE ${ }^{1} \&$ JACQUES G. HILL III² \\ ${ }^{1}$ Suranaree University of Technology, Nakhon Ratchasima, Thailand \\ ${ }^{2}$ Department of Biological Sciences, University of Arkansas, Fayetteville, AR, USA \\ ${ }^{*}$ Corresponding author e-mail: tyler.k.knierim@gmail.com
}

\begin{abstract}
An understanding of the spatial ecology of species living in and around human-dominated habitats is needed to develop conflict mitigation strategies and predict how organisms cope with ongoing anthropogenic habitat alteration. Here we present the results of a six-month telemetry study in Thailand of the banded krait (Bungarus fasciatus), a venomous elapid snake. We quantified home range size and habitat use of three adult kraits (1 male, 2 females) in an agricultural habitat. The kraits travelled an average of $47.20 \mathrm{~m} \pm 23.54 \mathrm{~m}$ between shelter sites and occupied home ranges of on average 21.45 ha \pm 19.56 ha (95\% dynamic Brownian Bridge Movement Models). They preferred to seek day time refuge amongst less disturbed habitat features, including waterways and rice paddy dykes, while avoiding routinely disturbed monoculture fields. The two female kraits also exhibited reduced movement while simultaneously attending their nests in a shared burrow complex. Fifteen neonates were observed emerging from the nest site. We recommend further investigation of banded krait reproductive ecology and ability to persist in heavily disturbed habitats.
\end{abstract}

\section{INTRODUCTION}

$\mathrm{B}^{\mathrm{s}}$ iodiverse tropical regions continue to undergo rapid habitat loss resulting from deforestation and agricultural expansion (Hughes, 2017; Imai et al., 2018). To conserve biodiversity, biologists and land managers must understand how species fulfil their essential life history activities in today's human-modified landscapes (Hansen \& Defries, 2007; Martínez-Abraín \& Jiménez, 2015). Human-wildlife conflict is among the leading threats faced by fauna across the globe (Torres et al., 2018) especially for species, such as the banded krait (Bungarus fasciatus), able to inflict injury to humans (Amarasinghe et al., 2015; Dickman, 2010; Dunham et al., 2010).

Banded kraits are a large, typically yellow and black banded, elapid snake that are distributed from India in the west to China in the east, and south into the Indonesian archipelago (The Reptile Database, 2017). They are nocturnal and thought to occur in a variety of habitats ranging from tropical evergreen forests to degraded areas near human inhabitation (IUCN, 2013; Purkayastha et al., 2011). Previous research has focused mostly on the potent venom of the banded krait, especially its therapeutic potential and the synthesis of anti-venom (Gomes et al., 2017). Despite the risks to human health posed by banded kraits across a wide geographic distribution (Tongpoo et al., 2018), there have yet to be any studies on the spatial ecology of this species. An understanding of the species spatial requirements, habitat use, and reproductive behaviour may provide valuable insight for assessing threats posed by humans to kraits and vice versa (Maritz et al., 2016). Herein we report the home range area estimates and habitat use of three radiotracked banded kraits (one male and two females) during a 6-month period (1 April 2017 - 30 September 2017). The kraits inhabited a riparian belt dominated by rice paddies in north-east Thailand. We also report observations on nest attendance by the two female kraits.

\section{MATERIALS AND METHODS}

We used radio-telemetry to track banded kraits in the Transitional Zone of the Sakaerat Biosphere Reserve (SBR), located in Nakhon Ratchasima, Thailand. The dominant land uses in the SBR's Transitional Zone are rice paddies, sugarcane fields, upland agriculture, irrigation canals, and villages. With the help of field technicians from 2015 to 2017, we implemented 354 man-hours of unstandardised night walking and road-cruise surveys to capture kraits throughout the SBR Transitional Zone. We surveyed various targeted locations in the Chiang Sa Tributary. The initial capture sites of the three kraits were located within $100 \mathrm{~m}$ of each other, within a retention pond complex characterised by a cluster of three shallow ponds bordered by a semi-natural and annually harvested wood stand, primarily composed of Eucalyptus camaldulensis, and spanning approximately 1.16 ha in area $\left(14.53^{\circ} \mathrm{N}, 101.97^{\circ} \mathrm{E}\right)$. The ponds were encircled by monocultures of sugarcane (Saccharum spp.) and rice (Oryza sativa). The average elevation across the study area, determined by creating a Minimum Convex Polygon (MCP) around all plotted krait locations, was $232 \mathrm{~m}$ a.s.l., and the dominant land use was irrigated rice $(65.43 \%)$, followed by human settlement (8.64\%). During our focal study period (1 April 2017 - 30 September 2017), terraced rice paddies were flooded with shallow water to enable rice growth. During the dry season (January - March) fields were drained, harvested and left fallow for livestock grazing, as is typical in north-east 
Thailand (Kanokkanjana \& Garivait, 2013).

We assigned each radio-tracked krait an identification code corresponding to the chronological order of capture (e.g. BUFA01, BUFA02, BUFA03). After capture, we anesthetised the kraits using isoflurane to reduce stress while recording morphometric measurements (Setser, 2007) such as body mass, snout-to-vent length (SVL), tail length ( $T L)$, and head dimensions. We used cloacal probing described by Laszlo (1975) to determine sex. A veterinarian from the Nakhon Ratchasima Zoo surgically implanted kraits with VHF radio transmitters, following the methodology outlined by Reinert \& Cundall (1982), with one of three transmitter models, (3.8 g SB-2, 9 g SI-2, and the 11 g SI-2 Holohil Inc., Ontario, Canada) depending on their availability. The ratio of transmitter mass to krait mass was $0.007 \pm 0.090 \%$ (mean \pm SD), significantly less than the maximum mass to body ratios recommended in telemetry studies of other vertebrates (Aldridge \& Brigham, 1988; Knapp \& Abarca, 2009).

We quantified spatial results using krait locations collected once daily, between 08:00 $\mathrm{h}$ and 18:00 h. So as not to stress the snakes, we avoided pinpoints during early mornings, nights and evenings to ensure that the nocturnal kraits were stationary within their daytime shelters. During the daytime, trackers followed the signal emitted from the internal radio transmitters to each krait's location, using an R410 ATS radio receiver in conjunction with an RA-23K C BA 17 Teleonics antennae. When a krait had moved to a new location from the previous track, trackers approached no closer than $6 \mathrm{~m}$, relying on triangulation to pinpoint the new location using the 'draw line' feature on a Garmin 64S GPS unit. When a krait remained at a new location for at least one successive day, trackers attempted to locate the krait's exact position by approaching within $1 \mathrm{~m}$ of the shelter site if the site was accessible by walking across exposed soil, ruling out the possibility of treading on an unseen snake obscured by vegetation.

We estimated home ranges from the day time krait locations using dynamic Brownian and Bridge Movement Models (dBBMM) following the modern methodology used by Karelus et al. (2017), Kranstauber et al. (2012) and Silva et al. (2018) to quantify utilisation distributions (UD) as home ranges from which to quantify habitat use. Unlike other home range estimation methods such as kernel density estimates, which do not account for spatially autocorrelated animal movement data (Kranstauber et al., 2012), dynamic Brownian Bridge movement models incorporate the temporal structure of animal locations to estimate UDs based on their movement's trajectory. We set the dBBMM moving window size to 15 (equivalent to 15 days) and a margin size of 3 to detect possible changes in movement between 3-day periods. Dynamic BBMM also requires input of the telemetry location error; we took this to be average GPS accuracy in the field ( $3 \mathrm{~m})$. We calculated dBBMM UD estimates using Program $R$ ( $R$ Core Team, 2017) in R Studio (R Studio Team, 2017), using packages 'BBMM' (Kranstauber et al., 2017), 'ctmm' (Fleming et al., 2017a), 'move' (Kranstauber et al., 2016), 'sp' (Pebesma \& Bivand, 2005), 'ggplot2' (Wickham, 2009), 'adehabitatHR' (Calenge et al., 2015), and 'rgdal' (Roger et al., 2017). We designated the $95 \%$ and $99 \%$ dBBMM isopleth contour utilisation distributions to represent areas of 'core utilisation' and a more generous 'total utilisation' as these larger contour values predict a more accurate area of use without over-smoothing (Walter et al., 2011).

We also report home range sizes using $100 \%$ minimum convex polygons (MCP). Despite their drawbacks, MCPs are easy to conceptualise and have been widely applied to home range estimation in previous reports of snake spatial ecology (Croak et al., 2013; Mohammadi et al., 2014; Stiles et al., 2017; Vanek \& Wasko, 2017). As a result of our small sample sizes, the power of robust statistical comparisons was limited, therefore we only report spatial results as descriptive statistics (mean \pm standard error) and limit our reporting to tracked kraits whose home ranges passed bootstrap analyses (i.e. non-asymptotic) as recommended by Marshall et al. (2018). We considered a home range asymptotic when the average home range size derived from $90 \%$ of randomly ordered krait shelter sites were within $10 \%$ of the home range estimate derived from the total shelter sites. Consequently, we were limited to reporting home range estimates only between the months of April - September 2017 as prior to, and following this 6-month period, tracking intervals were infrequent and irregular.

We estimated habitat use and availability on multiple scales, first using the $95 \%$ dBBMM estimates, to compare 'core use' areas to those available within the total $100 \%$ MCPs. Second, we evaluated shelter site preference by using Duncan's Index of Preference to calculate habitat use ratios from habitat at the krait diurnal locations (i.e. shelter sites) compared to the proportion each habitat comprised of the total home range (Duncan, 1983). We defined the areas within the $95 \%$ dBBMM UDs as available habitat from which to compare shelter site location habitats. We transformed preference scores, displaying them as log-normalised indices in which preference occurs when score values were greater than 0.3 , following Duncan's methodology. We categorised habitats into 10 dominant types within each study area, including: canals, a recently constructed canal, field dykes, field margins, human settlement, tree plantations, ponds, rice, roads, and sugarcane (descriptions in Table 1). We

Table 1. Description of available habitats within krait home ranges

\begin{tabular}{|c|c|c|}
\hline Habitat & Code & Description \\
\hline Rice & RCE & $\begin{array}{l}\text { Seasonally flooded rice (Oryza sativa) paddies } \\
\text { harvested } 2 / \text { year }\end{array}$ \\
\hline Sugarcane & SGN & $\begin{array}{l}\text { Sugarcane (Saccharum spp.) fields harvested 1/ } \\
\text { year }\end{array}$ \\
\hline Plantation & PLT & $\begin{array}{l}\text { Plantation forests of (Eucalyptus camaldulensis), } \\
\text { or mixed fruit orchards (>10 m at minimum width) }\end{array}$ \\
\hline Canal & CAN & $\begin{array}{l}\text { Irrigation canals and artificially channelized } \\
\text { streams ( }>3 \mathrm{~m} \text { wide) }\end{array}$ \\
\hline New Canal & $\mathrm{NCN}$ & $\begin{array}{l}\text { Recently constructed irrigation canal, baring } \\
\text { exposed, sparsely vegetated banks }\end{array}$ \\
\hline Pond & PND & Retention and fishponds \\
\hline Field Dyke & DKE & $\begin{array}{l}\text { Narrow embankments subdividing rice paddies (< } \\
2 \mathrm{~m} \text { wide) and ( } 91 \mathrm{~cm} \pm 53 \mathrm{~cm} \text { high) }\end{array}$ \\
\hline $\begin{array}{l}\text { Field } \\
\text { Margin }\end{array}$ & MGN & $\begin{array}{l}\text { Either a depression or embankment linearly divid- } \\
\text { ing habitat types (> } 2 \mathrm{~m} \text { wide) }\end{array}$ \\
\hline Settlement & SET & Actively used buildings and surrounding lot \\
\hline Roads & ROD & Paved or dirt ( $3-5 \mathrm{~m}$ in width) \\
\hline
\end{tabular}




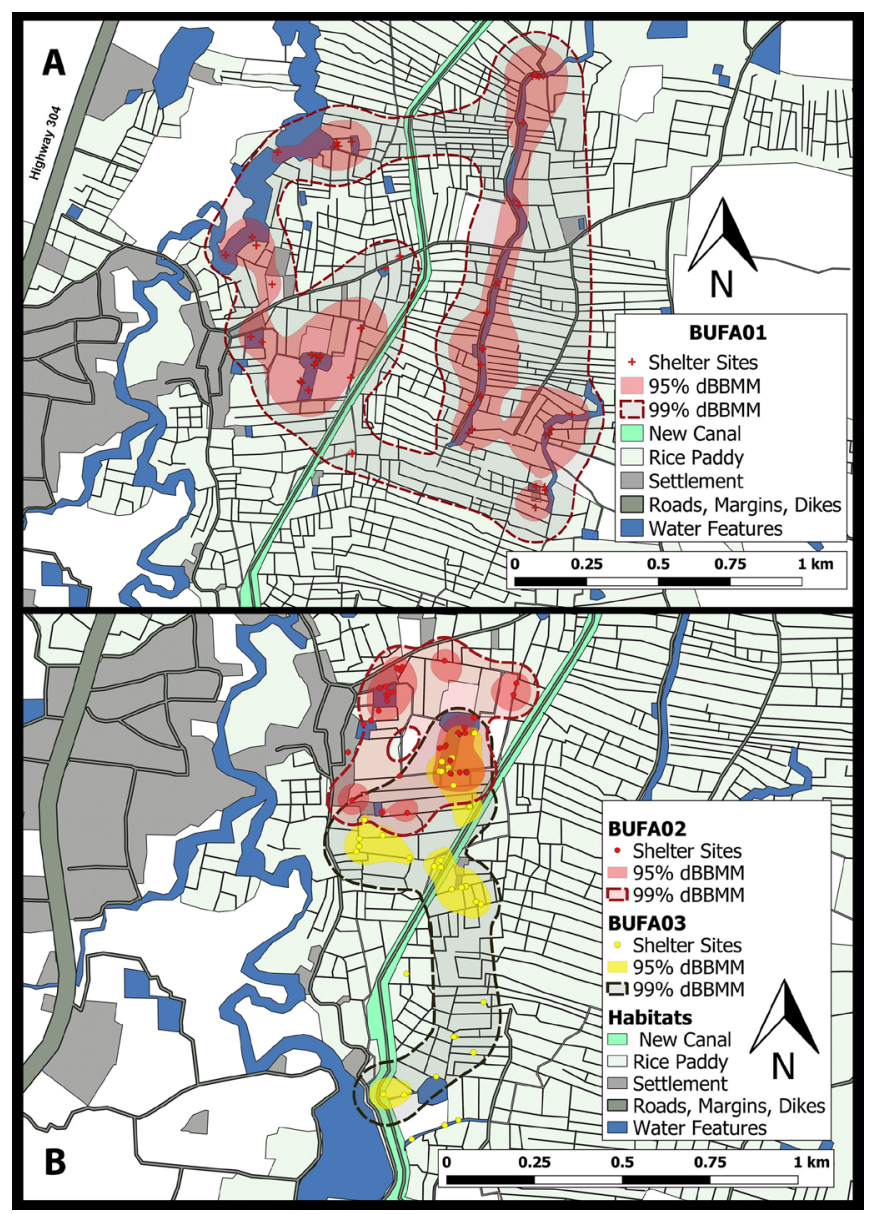

Figure 1. Map of the dynamic Brownian Bridge movement model utilisation distribution for Bungarus fasciatus, A) The single adult male (BUFA01), B) The two adult females (BUFA02 \& BUFA03). Different levels of utilisation indicated by $95 \%$ and $99 \%$ contours represent greater and lesser use.

Table 2. Summary of tracking periods and basic biometric attributes of the three radio-tracked banded kraits recorded from their initial capture

\begin{tabular}{|c|c|c|c|c|c|c|}
\hline $\begin{array}{l}\text { Snake } \\
\text { ID }\end{array}$ & $\begin{array}{l}\text { Capture } \\
\text { date }\end{array}$ & $\begin{array}{l}\text { Last track } \\
\text { date }\end{array}$ & Sex & $\begin{array}{c}\text { Mass } \\
\text { (g) }\end{array}$ & $\begin{array}{c}\text { SVL } \\
(\mathrm{mm})\end{array}$ & $\begin{array}{c}\text { Transmitter } \\
\text { type }\end{array}$ \\
\hline BUFA01 & 2015-08-16 & 2017-11-22 & M & 1449 & 1576 & $\begin{array}{l}\text { Holohil SI-2: } \\
11 \mathrm{~g}, 33 \times 11 \mathrm{~mm}\end{array}$ \\
\hline BUFA02 & $2016-11-26$ & 2017-11-30 & $\mathrm{F}$ & 642.8 & 1341 & $\begin{array}{l}\text { Holohil SI-2: } \\
9 \mathrm{~g}, 33 \times 11 \mathrm{~mm}\end{array}$ \\
\hline BUFA03 & 2017-03-14 & 2017-10-12 & $\mathrm{F}$ & - & 1131 & $\begin{array}{l}\text { Holohil SB-2: } \\
3.8 \mathrm{~g}, 14 \times 9.5 \mathrm{~mm}\end{array}$ \\
\hline
\end{tabular}

digitised habitat features from Google Maps (2018) satellite imagery in QGIS (Quantum GIS Development Team, 2018). Indistinguishable habitat patches were subsequently visited in person on the ground for correct classification.

From 04 April 2017 to 01 July 2017, we used time-lapse photography to monitor a shared nesting site containing several burrow entrances used by the two radio-tracked female kraits. This enabled us to confirm nest attendance by the female kraits and photograph hatchling neonates as they emerged from below ground. We positioned two Bushnell field cameras (Trophy Cam HD Essential E3, Model: 119837) with infrared night capability on tripods spaced approximately $2-3 \mathrm{~m}$ from the focal nesting location. Cameras were programmed to each capture 1 still-image per minute. Each image displayed the ambient temperate and time taken. Field technicians replaced camera batteries and SD cards daily during their regular radio tracks of each krait.

\section{RESULTS}

\section{Spatial ecology}

We report the home range sizes of three radio-tracked banded kraits from 01 April - 30 September 2017, details of these snakes are shown in Table 2. Based on the 481 unique diurnal fixes, home range estimate means varied between 21.45 ( $\pm 19.56 \mathrm{ha}$ ) for the $95 \% \mathrm{dBBMM}, 61.72$ ( $\pm 51.88 \mathrm{ha}$ ) for the $99 \%$ dBBMM, and 57.26 ( \pm 50.04 ha) for $100 \%$ MCP. There were no instances of active movement or arboreal space use by the kraits during the 481 total diurnal tracks occurring between 08:00 - 18:00 h, throughout the study period.

On average, mean daily displacement (MDD) of kraits was $47.20 \pm 23.54 \mathrm{~m}$. BUFA01, the single adult male had the greatest MDD (79.69 m), while the two female kraits moved less than half the daily distance than the single tracked male (Table 3). We failed to make daily diurnal tracking fixes so that we only have on average $26.7 \pm 1.6$ days tracked/month; consequently, in Table 3 we have included values for mean displacement between fixes (MDF).

\section{Habitat use}

Based on the proportion of potential habitat types within each home range estimate, kraits selected permanent water features (ponds and canals) above all else. Field margins and dykes comprised the smallest portion of the land cover in each home range; however, they represented a slightly higher proportion of dBBMM estimates, indicating higher selection. Human settlements were used in slightly higher proportion than their availability $(3.42 \% \pm 3.25 \% \mathrm{dBBMM}$ and $1.36 \%$ $\pm 0.81 \mathrm{MCP}$ ) but this may be the result of their association with adjacent aquaculture ponds (Fig. 1). Rice monoculture

Table 3. Movement and home range size from the simultaneous tracking period (April - September 2017) for each krait, MDF - mean displacement between fixes; MDD - mean daily displacement; MCP - minimum convex polygon calculated from $100 \%$ of locations; 'Unique shelters' - the number of individual shelter sites used; 'Revisited shelters' - shelter sites used more than once

\begin{tabular}{|c|c|c|c|c|c|c|c|c|c|}
\hline Snake ID & Fixes & Relocations & $\operatorname{MDF}(\mathrm{m})$ & $\operatorname{MDD}(\mathrm{m})$ & $\begin{array}{l}\text { MCP } \\
\text { (ha) }\end{array}$ & $95 \%$ dBBMM & $99 \%$ dBBMМ & $\begin{array}{l}\text { Unique } \\
\text { shelter }\end{array}$ & $\begin{array}{c}\text { Revisited } \\
\text { shelters }\end{array}$ \\
\hline BUFA01 & 161 & 58 & 221.2 & 79.69 & 127.33 & 49.10 & 134.88 & 48 & 6 \\
\hline BUFA02 & 161 & 36 & 110.35 & 24.67 & 13.60 & 7.10 & 20.28 & 34 & 3 \\
\hline BUFA03 & 159 & 46 & 128.72 & 37.25 & 30.85 & 8.14 & 30.00 & 38 & 5 \\
\hline
\end{tabular}


was the most abundant potential habitat across all home range estimates (Fig. 2A). However, rice paddies comprised a smaller portion of the more accurate $95 \%$ dBBMMs $(57.47 \%$ $\pm 5.23 \%)$ than the less accurate $100 \%$ MCPs $(67.65 \% \pm 10.16$ $\%$ ), indicating an overall avoidance of open rice paddies (Fig. 2B).

Preference indices derived from shelter site locations varied across the three individuals (Fig. 2B). Preferred habitats by BUFA01 included field margins, pond banks, canals, and to a lesser extent, the paddy dykes. The two females showed shelter site preference for field margins, paddy dykes, and pond banks. However, the male (BUFA03)

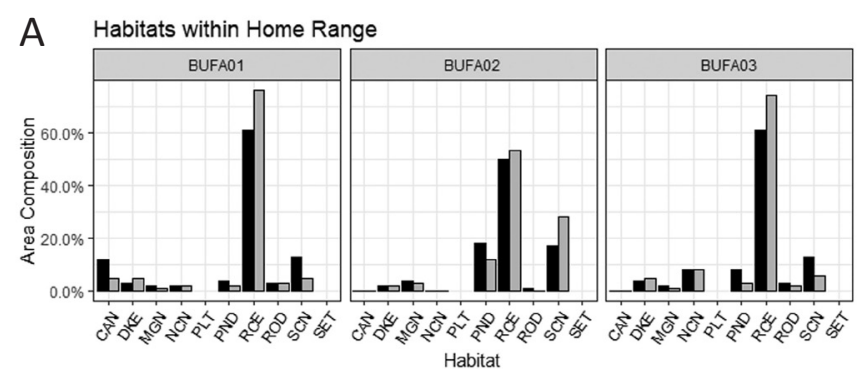

B Habitat Preference within Home Range

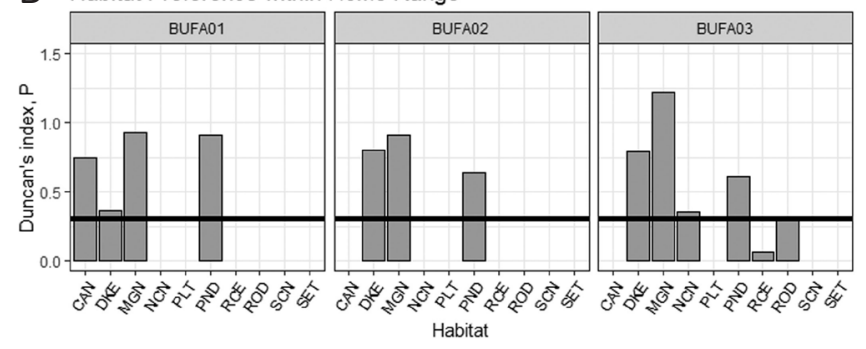

Figure 2. Habitat Preference A) Percent composition of $95 \%$ dBBMM (black) and $100 \%$ MCP (grey) home range estimates, B) Habitat preference indices for kraits using log-normalised Duncan's Index. Preferences calculated from $95 \%$ dBBMM utilisation distribution. Habitat codes: CAN- canal, DKE- paddy dyke, MGN- field margin, NCN - new canal, PLT - plantation forest, PND - pond, RCE - rice paddies, ROD - road, SCN - sugarcane fields, SET - settlement. Preference occurs above 0.30 (indicated by line). was the only individual to shelter amongst the sparsely vegetated banks of a recently constructed canal (NCN, Fig. 2B), which was available to all three snakes. BUFA03 also had slight preference for roadsides. Agricultural fields were again avoided, with preference scores falling far below the 0.30 preference threshold for each krait (Fig. 2B).

\section{Nest attendance}

While attending their nests, the two females simultaneously shared the same burrow complex for 64 days, BUFA02 (14 April - 01 July 2017; 75 days) and BUFA03 (04 April - 17 June 2017; 77 days). Both females were radio-located at their nest site throughout this period except for 8 separate days spent at nearby shelter sites (BUFA02) and 1 day each at 2 separate shelter sites (BUFA03). During the nesting period the MDDs of BUFA02 and BUFA03 were only $13.76 \mathrm{~m}$ and $12.56 \mathrm{~m}$ respectively, which amounted to a reduction by 58 $\%$ and $77 \%$ when compared with the MDDs for the nonnesting period in the dry and rainy season of 2017. Both females moved less frequently during nesting but when they did move the resulting displacements were greater than those seen between shelter sites during non-nesting periods. Frequency of relocations during the nesting period was also reduced for both females. However, MDFs were greater as their infrequent moves between the short-term shelter sites and the nesting site were farther than the mean MDDs during non-nesting periods (Table 3). The dBBMM movement variance did not differ significantly between the two females while nesting (two-sample Kolmogorov Smirnov test $D=0.108, p=0.59$ ). The movement variance of the single male, BUFA01, did not change during the nesting period as the snake continued to make frequent, long-distance moves compared to the females (Fig. 3).

\section{Neonate emergence}

At the nesting site, we observed 15 neonates emerge from three separate burrow entrances within an approximately $2 \mathrm{~m}$ long strip of raised field margin, measuring approximately $1.4 \mathrm{~m}$ wide and $1.2 \mathrm{~m}$ high, separating a sugarcane and

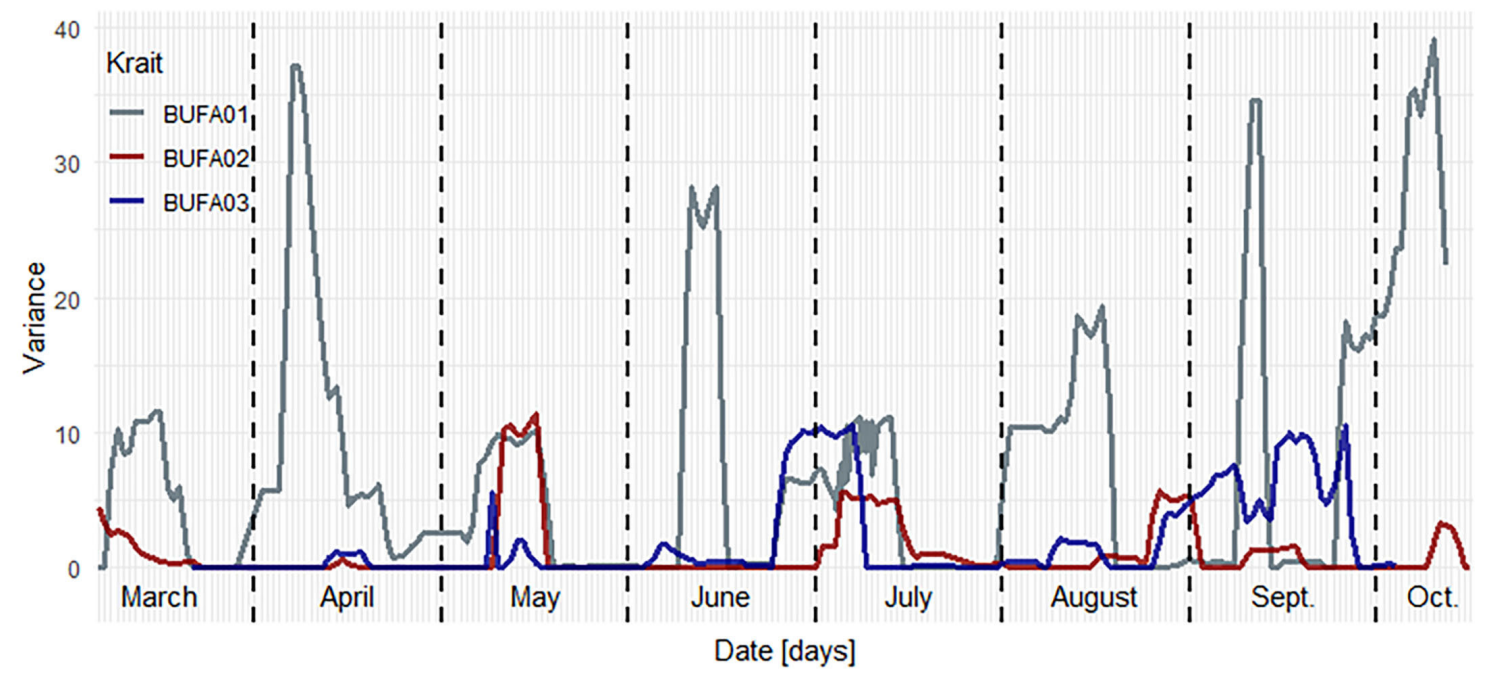

Figure 3. Variance estimation $\left(\sigma^{2} \mathrm{~m}\right)$ over time for the three kraits showed a subtle drop in movement activity during the nesting period for the two females (BUFA02 \& BUFA03) between April - June. However, the single adult male (BUFA01) continued to make major movements throughout the same period. 
Table 4. Field camera records of neonate $B$. fasciatus emerging from a shared nesting chamber and some basic biometric attributes of the captured individuals. The field cameras were set to record 1 frame/minute.

\begin{tabular}{|c|c|c|c|c|c|c|c|}
\hline \multirow[b]{2}{*}{ Neonate ID } & \multicolumn{2}{|c|}{ Emergence from nest } & \multirow[b]{2}{*}{ No. photo frames } & \multirow[b]{2}{*}{ Temp. $\left({ }^{\circ} \mathrm{C}\right)$} & \multirow[b]{2}{*}{ Sex } & \multirow[b]{2}{*}{ Mass (g) } & \multirow[b]{2}{*}{ SVL $(\mathrm{cm})$} \\
\hline & Date & Time & & & & & \\
\hline 1 & 24 June & 01:10 & 3 & 22 & - & - & - \\
\hline 2 & & $02: 23$ & 8 & 22 & - & - & - \\
\hline 3 & 25 - 26 June & 21:59 & NA & 25 & Male & 332 & 15.9 \\
\hline 4 & & 02:05 & NA & 25 & Male & 342 & 16 \\
\hline 5 & & $02: 51$ & NA & 25 & Male & - & 14.7 \\
\hline 6 & 28 - 29 June & $21: 12$ & 9 & 26 & - & - & - \\
\hline 7 & 30 June & $00: 25$ & 6 & 25 & - & - & - \\
\hline 8 & 06 - 07 July & $20: 51$ & 1 & 26 & - & - & - \\
\hline 9 & & $23: 48$ & 3 & 22 & - & - & - \\
\hline 10 & & 00:05 & 2 & 25 & - & - & - \\
\hline 11 & & 00:08 & 6 & 25 & - & - & - \\
\hline 12 & & 01:42 & 2 & 24 & - & - & - \\
\hline 13 & & 03:30 & 14 & 24 & - & - & - \\
\hline 14 & & 19:19 & 1 & 23 & - & - & - \\
\hline 15 & 07 July & $20: 24$ & 8 & 22 & - & - & - \\
\hline
\end{tabular}

cassava field. The first two emerged on the night of 23 June 2017, followed by 3 individuals the following night and 2 individuals on subsequent nights (28 - 30 June). A second batch of 6 individuals emerged on the night of 06 July 2017 accompanied by 2 more the following night. The first 7 neonates to emerge likely belonged to BUFA03, the first female to arrive at the nest site on 04 April 2017 and the last 8 individuals to BUFA02, who arrived on 14 April 2017. Our field cameras, set to capture 1 image at the same time every minute, recorded in situ neonates on a total of 55 photoframes, with a mean of 4.58 frames (i.e. minutes) to disperse from the nest site and immediate surrounding field margin. Temperature stamps on emergence frames ranged from $23^{\circ}-$ $26^{\circ} \mathrm{C}$. We monitored the nest site with field personnel on the night of 25 June 2017 and managed to physically capture and make measurements of three individuals as they emerged from a nest burrow (Table 4).

\section{DISCUSSION}

Our study demonstrates that banded kraits have relatively large home ranges and preferred micro-habitats such as waterways, rice paddy dykes, and field margins when inhabiting farmland. Undisturbed micro-habitats may be a key factor in the continued persistence of kraits by facilitating important life history events (sheltering, foraging, mating, and nesting). Our observations on krait nesting activity also highlight the need for further investigation into elapid reproductive biology. Nest attendance while sharing space by our two females may provide preliminary evidence of parental care and sociality in banded kraits.

However, any conclusions drawn from our study are limited as observations were based on a sample of only three snakes. Despite extensive night surveys, we were only able to capture four adult individuals to radio-track (1 krait/118 survey man-hours) and maintained only 3 individuals long enough to report meaningful observations.

Parental care in snakes has been documented from viviparous species of Viperidae and Pythonidae (Alexander, 2018; Brashears \& Denardo, 2012) and may be a more prevalent trait among temperate snake species (Butler et al., 1995; Clark et al., 2012; Halliwell et al., 2018; Hill III et al., 2006; Muellman et al., 2018). In elapid snakes, reports of nest attendance or other parental behaviour is limited to female king cobras (Ophiophagus hannah) guarding the nests they build from vegetation on the forest floor (Dolia, 2018; Whitaker et al., 2013) and Indochinese spitting cobras (Naja siamensis) guarding egg clutches for the complete egg incubation period in Thailand (B. Nadolski personal communication, 2019). Previous observations of the nesting behaviour of kraits have been limited to captive specimens of Bungarus flaviceps (Chanhome, 2014). Interestingly, the two female kraits in our study shared the same burrow complex while nesting. We are unsure to what extent they shared space below ground; however, both snakes were observed on camera entering and exiting the same set of burrow entrances. As far as we are aware, there are no previous reports of communal nesting or maternal sociality in wild elapid snakes.

Four habitat features (ponds, margins, canals, dykes) had the highest preference scores (Fig. 2B), despite accounting for only $16.15 \%$ of land area across the three snake's study areas. In a separate study, an individual Malayan krait (Bungarus candidus) in an upland agricultural area in the SBR also showed strong preference for a vegetated field margin (Knierim et al., 2018). Similarly, king cobras (Ophiophagus hannah) in the SBR prefer irrigation canals and field margins in agricultural landscapes (Marshall et al., 2018); canals may 
serve as movement corridors for snakes through unfavourable landscapes (Whitaker \& Shine, 2000).

Rice paddy dykes and termite mounds have been shown to serve as biodiversity reservoirs for micro fauna and arthropods in rice dominated agricultural systems of northeast Thailand (Choosai et al., 2009; Ichihara et al., 2014).

Paddy dykes are also important micro-habitat features for some vertebrates, hosting higher abundances of field paddy rats (Rattus argentiventer) in Indonesia (Brown et al., 2001), and tree frogs (Dryophytes japonicus \& Dryophytes suweonensis) in South Korea (Groffen et al., 2018). Surveys of rice fields for $R$. argentiventer burrow entrances by Brown et al. (2001), identified field dykes and canals as the two micro-habitats having the highest densities of rat burrows. Both rodents and amphibians may serve as potential prey items for banded kraits (Chan-ard et al., 2015). Furthermore, the burrows excavated by rodents provided kraits in our study with structural refuges for sheltering and nesting in an exposed landscape that is subject to frequent disturbance from farming activities.

Ultimately, the preference for field margin and water features in agricultural habitats is likely related to the disturbance levels or availability of prey and shelter sites. Habitat use by snakes is often explained by multiple factors (Heard et al., 2004). Therefore, assessments of microhabitat characteristics at known krait shelter sites should test hypotheses to further our inquiry. Future work should also assess the micro-habitat features surrounding krait's diurnal retreats, mating, and nesting sites. Animal burrows can be a limited resource, providing shared refuge for an array of species in otherwise harsh environments (Hofstede \& Dziminski, 2017; Pike \& Mitchell, 2013), and we therefore expect them to be a key enabling feature in the persistence of snakes and other taxa in agricultural habitats.

Our conclusions on krait spatial ecology and habitat selection are limited and largely unsupported quantitatively due to our difficulty in radio tracking an adequate sample size of kraits. Future research on banded krait ecology should attempt to radio track a larger sample to give quantitative assessments of spatial and habitat requirements. Banded kraits are known to occur in different habitats than those in our study, including coastal wetlands and major cities, (Kurniawan et al., 2018; Purkayastha et al., 2011). Their use of these habitats is also worthy of future study.

\section{ACKNOWLEDGEMENTS}

We would like to thank the Thailand Institute of Science and Technological Research (TISTR) and The National Research Council of Thailand (NRCT) for funding and permitting this project. We are also grateful to Dr. Wironrong Changphet of the Nakhon Ratchasima Zoo for performing surgical operations. Our research methods were carried out with the approval of Suranaree University of Technology's animal use and ethics committee and permitted by the National Research Council of Thailand (permit No. 0002/10662).

\section{REFERENCES}

Aldridge, H.D.J.N. \& Brigham, R.M. (1988). Load carrying and maneuverability in an insectivorous bat: a test of the $5 \%$ "rule" of radio-telemetry. Journal of Mammalogy 69: 379-382.

Alexander, G.J. (2018). Reproductive biology and maternal care of neonates in southern African pythons (Python natalensis). Journal of Zoology 305: 141-48.

Amarasinghe, A.A.T., Madawala, M.B., Karunarathna, D.M.S.S., Manolis, S.C., Silva, A. \& Sommerlad, R. (2015). Humancrocodile conflict and conservation implications of saltwater crocodiles Crocodylus porosus (Reptilia: Crocodylia) in Sri Lanka. Journal of Threatened Taxa 7: 7111-7130.

Barnes, C.H., Strine, C.T., Suwanwaree, P. \& Hill III, J.G. (2017). Movement and home range of green pit vipers (Trimeresurus Spp.) in a rural landscape in north-east Thailand. The Herpetological Bulletin 142: 19-28.

Berger-Tal, O., Polak, T., Oron, A., Lubin, Y., Kotler, B.P. \& Saltz, D. (2011). Integrating animal behavior and conservation biology: a conceptual framework. Behavioral Ecology 22: 236-39.

Brashears, J. \& Denardo, D.F. (2012). Do brooding pythons recognize their clutches? Investigating external cues for offspring recognition in the children's python, Antaresia childreni. Ethology 118: 793-98.

Brown, P.R., Singleton, G.R. \& Sudarmaji (2001). Habitat use and movements of the rice-field rat, Rattus argentiventer, in West Java, Indonesia. Mammalia 65:151-166.

Butler, J.A., Hull, T.W. \& Franz, R. (1995). Neonate aggregations and maternal attendance of young in the eastern diamondback rattlesnake, Crotalus adamanteus. Copeia 1995: 196-98.

Chan-ard, T., Nabhitabhata, J. \& Parr., J.W. (2015). A Field Guide to the Reptiles of Thailand. Oxford University Press, 314 pp.

Chanhome, L. (2014). Reproduction of the red-headed krait (Bungarus flaviceps) in captivity. Tropical Natural History 13: 59-63.

Choosai, C., Mathieu, J., Hanboonsong, Y. \& Jouquet, P. (2009). Termite mounds and dykes are biodiversity refuges in paddy fields in north-eastern Thailand. Environmental Conservation 36: 71.

Clark, R.W., Brown, W.S., Stechert, R. \& Greene, H.W. (2012). Cryptic sociality in rattlesnakes (Crotalus horridus) detected by kinship analysis. Biology Letters 8: 523-525.

Dickman, A.J. (2010). Complexities of conflict: the importance of considering social factors for effectively resolving human - wildlife conflict. Animal Conservation 13: 458-66.

Dolia, J. (2018). Notes on the distribution and natural history of the king cobra (Ophiophagus hannah Cantor, 1836) from the Kumaon Hills of Nepal. Herpetology Notes 11: 217-22.

Duncan, P. (1983). Determinants of the use of habitat by horses in a Mediterranean wetland. The Journal of Animal Ecology 93-109.

Dunham, K.M., Ghiurghi, A., Cumbi, R. \& Urbano, F. (2010). Human-wildlife conflict in Mozambique: a national perspective, with emphasis on wildlife attacks on humans. Oryx 44: 185-193.

Frédéric, A., Eva, H.D., Stibig, H., Mayaux, P., Gallego, J., Richards, T. \& Malingreau, J. (2002). Determination of deforestation rates of the world's humid tropical forests. 
Science 297: 999-1002.

Gomes, A., Saha, P.P., Bhattacharya, S., Ghosh, S., \& Gomes, A. (2017). Therapeutic potential of krait venom. Toxicon 131: 48-53.

Groffen, J., Borzée, A. \& Jang, Y. (2018). Preference for natural borders in rice paddies by two treefrog species. Animal Cells and Systems 22: 205-11.

Halliwell, B., Uller, T., Holland, B.R. \& While, G.M. (2018). Reptiles. Nature Communications 8: 1-8.

Hansen, A.J. \& Defries, R. (2018). Ecological mechanisms linking protected areas to surrounding lands. Ecological Applications 17: 974-88.

Hart, K.M., Cherkiss, M.S., Smith, B.J., Mazzotti, F.J., Fujisaki, I., Snow, R.W. \& Dorcas, M.E. (2015). Home range, habitat use, and movement patterns of non-native Burmese pythons in Everglades National Park, Florida, USA. Animal Biotelemetry 3: 1-13.

Heard, G.W., Black, D. \& Robertson, P. (2004). Habitat use by the inland carpet python (Morelia spilota metcalfei: Pythonidae): seasonal relationships with habitat structure and prey distribution in a rural landscape. Austral Ecology 29: 446-460.

Hill III, J.G, Chanhome, L., Artchawakon, T., Thirakhump, K. \& Voris, H.K. (2006). Nest attendance by a female malayan pit viper (Calloselasma rhodostoma) in northeast Thailand. The Natural History Journal of Chulalongkorn University 6: 57-66.

Hofstede, L. \& Dziminski, M.A. (2017). Greater bilby burrows: important structures for a range of species in an arid environment. Australian Mammalogy 39: 227-37.

Hughes, A. (2017). Understanding the drivers of southeast Asian biodiversity loss. Ecosphere 8: 1-33.

Ichihara, M., Matsuno, K., Inagaki, H., Saiki, C., Mizumoto, S., Yamaguchi, S., Yamashita, M. \& Sawada, H. (2014). Creation of paddy levees to enhance the ecosystem service of weed seed predation by crickets. Landscape and Ecological Engineering 11: 227-233.

Imai, N., Furukawa, T., Tsujino, R., Kitamura, S. \& Yumoto, T. (2018). Factors affecting forest area change in southeast Asia during 1980-2010. PLoS ONE: 1-14.

International Union for Conservation of Nature. (2013). IUCN Red List of Threatened Species. http://www. iucnredlist. org (accessed April 2019)

Kanokkanjana, K. \& Garivait, S. (2013). Alternative rice straw management practices to reduce field open burning in Thailand. International Journal of Environmental Science and Development 4: 119-23.

Karelus, D.L., McCown, J.W., Scheick, B.K. \& Oli, M.K. (2018). Micro-habitat features influencing habitat use by Florida black bears. Global Ecology and Conservation 13(2017): e00367.

Knapp, C.R. \& Abarca, J.G. (2009). Effects of radio transmitter burdening on locomotor ability and survival of iguana hatchlings. Herpetologica 65: 363-372.

Knierim, T.K., Marshall, B.M., Hayes, L., Suwanwaree, P. \& Strine, C.T. (2018). The movements and habitat preferences of a Malayan Krait (Bungarus candidus) in an agrarian landscape. The Herpetological Bulletin 143: 30-33.

Kranstauber, B., Kays, R., Lapoint, S.D., Wikelski, M. \& Safi, K. (2012). A dynamic Brownian Bridge Movement Model to estimate utilization distributions for heterogeneous animal movement. Journal of Animal Ecology 81: 738-746.

Kranstauber B., Smolla, M. \& Scharf, A.K. move: visualizing and analyzing animal track data. $R$ package version 3.0.1. 2017: http://CRAN.R-project.org/package=move.

Kurniawan, N., Firdaus, A.S., Nugraha, F.A.D., Maulidi, A. \& Kurianto, A.S. (2018). Fishermen's perspective on herpetofauna: a case study from Kuala Tungkal. The Journal of Tropical Life Science 8: 1-5.

Laszlo, J. (1975). Probing as a practical method of sex recognition in snakes. International Zoo Yearbook 15: 178-79.

Loughran, Caleb L., Beck, Daniel D. \& Weaver, R.E. (2015). Use of communal shedding sites by the northern pacific rattlesnake (Crotalus oreganus oreganus) in central Washington State. Northwestern Naturalist 96: 156-60.

Luo, Y., Fu, H. \& Traore, S. (2014). Biodiversity conservation in rice paddies in China: toward ecological sustainability. Sustainability 6: 6107-24.

Maritz, B., Penner, J., Martins, M., Crnobrnja-Isailović, J., Spear, S., Alencar, L.R.V., Sigala-Rodriguez, J., Messenger, K., Clark, R.W., Soorae, P., Luiselli, L., Jenkins, C., \& Greene, H.W. (2016). Identifying global priorities for the conservation of vipers. Biological Conservation 204: 94-102.

Marshall, B.M., Strine, C.T., Jones, M.D., Artchawakom, T., Silva, I., Suwanwaree, P. \& Goode, M. (2018). Space fit for a king: spatial ecology of king cobras (Ophiophagus hannah) in Sakaerat Biosphere Reserve, north-eastern Thailand. Amphibia-Reptilia 40: 163-178.

Marshall, B.M., Strine, C.T., Jones, M.D., Theodorou, A., Amber, E., Waengsothorn, S., Suwanwaree, P. \& Goode, M. (2018). Hits close to home: repeated persecution of king cobras (Ophiophagus hannah) in northeastern Thailand. Tropical Conservation Science 11: 1-14.

Martínez-Abraín, A. \& Jiménez, J. (2015). Anthropogenic areas as incidental substitutes for original habitat. Conservation Biology 30: 593-98.

Mohammadi, S., Kluever, B.M., Tamashiro, T., Amano, Y. \& Hill III, J.G. (2014). Spatial and thermal observations of a Malayan krait (Bungarus candidus) from Thailand. Tropical Natural History 14: 21-26.

Muellman, P.J., Cunha, O.D. \& Montgomery, C.E. (2018). Crotalus horridus (Timber Rattlesnake) Maternal scent trailing by neonates. Northeastern Naturalist 25: 50-55.

Myers, N., Mittermeier, R.A., Mittermeier, C.G., Fonseca, G.A.B. \& Kent, J. (2000). Biodiversity hotspots for conservation priorities. Nature 403: 853-58.

Pe, T., Myint, T., Htut, A., Htut, T., Myint, A.A. \& Aung, N.N. (1997). Envenoming by Chinese krait (Bungarus multicinctus) and banded krait (B. fasciatus) in Myanmar. Transactions of the Royal Society of Tropical Medicine and Hygiene 91: 686-688.

Pike, D.A. \& Mitchell, J. C. (2013). Burrow-dwelling ecosystem engineers provide thermal refugia throughout the landscape. Animal Conservation 16: 694-703.

Purkayasth, J., Das, M. \& Sengupta, S. (2011). Urban herpetofauna: a case study in Guwahati City of Assam, India. Herpetology Notes 4: 195-202.

Reinert, H. \& Cundall, D. (1982). An improved surgical implantation method for radio-tracking snakes. Copeia 
1082: 702-5.

Rosa, I.M.D., Smith, M.J., Wearn, O.R., Purves, D., Ewers, R.M., Rosa, I.M.D., Smith, M.J., Wearn, O.R., Purves, D. \& Ewers, R.M. (2016). The environmental legacy of modern tropical deforestation. Current Biology 26: 2161-66.

Row, J. \& Blouin-Demers, G. (2006). Kernels are not accurate estimators of home-range size for herpetofauna. Copeia 4: 797-802.

Seaman, D.E. \& Powell, R.A. (1996). An evaluation of the accuracy of kernel density estimators for home range analysis. Ecology 77: 2075-85.

Setser, K. (2007). Use of anesthesia increases precision of snake length measurements. Herpetological Review 38: 409-11.

Silva, I., Crane, M., Suwanwaree, P., Strine, C. \& Goode, M. (2018). Using dynamic Brownian Bridge Movement Models to identify home range size and movement patterns in king cobras. PloS one 13(9): p.e0203449.

Strine, C., Silva, I., Barnes, C.H., Marshall, B.M., Artchawakom, T., Hill, J. \& Suwanwaree, P. (2018). Spatial ecology of a small arboreal ambush predator, Trimeresurus macrops Kramer, 1977, in northeast Thailand. Amphibia-Reptilia: 1-11.

The Reptile Database. (2017). Bungarus facsiatus. http:// www.reptile-database.org (accessed December 2017)

Tongpoo, A., Sriapha, C., Pradoo, A., Udomsubpayakul, U., Srisuma, S., Wananukul, W. \& Trakulsrichai, S. (2018). Krait envenomation in Thailand. Therapeutics and Clinical Risk Management 14: 711.
Torres, D.F., Oliveira, E.S. \& Alves, Rômulo R.N. (2018). Understanding human-wildlife conflicts and their implications. Ethnozoology: 421-445.

Trimble, M.J. \& Van Aarde, R.J. (2012). Geographical and taxonomic biases in research on biodiversity in humanmodified landscapes. Ecosphere 3: 1-16.

Vanek, J.P. \& Wasko, D.K. (2017). Spatial ecology of the eastern hog-nosed snake (Heterodon platirhinos) at the northeastern limit of its range. Herpetological Conservation and Biology 12: 109-18.

Walter, W.D., Fischer, J.W., Baruch-Mordo, S. \& VerCauteren, K.C. (2011). What is the proper method to delineate home range of an animal using today's advanced GPS telemetry systems: the initial step. Modern telemetry. IntechOpen.

Whitaker, N., Shankar, P.G., \& Whitaker, R. (2013). Nesting ecology of the king cobra (Ophiophagus hannah) in India. Hamadryad 36: 101-7.

Whitaker, P.B. \& Shine, R. (2000). Sources of mortality of large elapid snakes in an agricultural landscape. Journal of Herpetology 34: 121-128.

Wood, C., Qiao, Y., Li, P., Ding, P., Lu, B., \& Xi, Y. (2010). Implications of rice agriculture for wild birds in China. Waterbirds 33: 30-43.

Accepted: 7 October 2019 